\title{
Treatment of Edentulousness by Combined Implantation and Reduced Dentures: A Case Report
}

\author{
Slavoljub Tomić* \\ Department of Oral Surgery, University of East Sarajevo, Bosnia and Herzegovina
}

*Corresponding author: Slavoljub Tomić, Faculty of Medicine, Department of Oral Surgery, University of East Sarajevo, Foča, Bosnia and Herzegovina, Tel: +38765944676

\begin{abstract}
Summary
Finding the optimal solution for total numbness, which would satisfy all the principles of the modern dental profession, and thus the patient itself, is still a matter of the skills of a surgeon and prosthetist, but also a compromise with the patient, which should in no way compromise with the postulates of dental implantology. This is a presentation of the care of a 65-year-old patient who appeared in a private dental clinic for the solution of total heartlessness, among which the implant-prosthetic therapy, which she accepted, was also proposed.
\end{abstract}

\section{Keywords}

Edentulousness, Dental implants, Total denture

\section{Introduction}

Dental patients have the need and desire that, in conditions where there is no other solution than mobile prostheses, they are such that they allow normal nutrition, while not stretching from their failure in function, which is particularly pronounced in the lower jaw with pronounced a reduced residual alveolar ridge. Also, many of them express their desire, especially when it comes to the upper total prosthesis, that the taste of foods is maximal, which from a dental aspect means reduction of the prosthesis in the palate area. Some patients and the profession they deal with tend to special requests (singers, actors, wine and food tasting), since the prostheses also lead to phonetic changes, except for the already mentioned inability to feel the taste of food and drink completely. Therefore, the fulfillment of these demands, which, if they do not strike with the indication, are quite acceptable, moreover and preferably [1].
Reduction of the denture in the upper jaw causes a decrease in the total dentition retention, but therefore the implanted implants do so contribute to its stabilization [2-4]. Several studies have shown that a minimum of four implants in the upper jaw should be recommended in order to reduce the denture plate, without affecting its stability [4-8]. The region of the eyebrows is crucial in the positioning of the implants, but the posterior site is questionable, since in the region of molars it is also the largest chewing force [9]. In addition, the molar region has a lower resorption rate compared to the premolar region [10]. However, the premolar region can be used to implant implants in order to avoid the replacement of the residual alveolar ridge (augmentation) and lift the maxillary sinus floor-sinus lift $[1,11]$.

For the positioning of the implants in the lower jaw, the same principle applies as in the above and there is a good static positioning [12], and the same localization as in the upper jaw is preferable. Examination of the design of the dental implants for total dentures and their impact on stability have been the subject of numerous studies [13-15], but the positioning of implants and their impact on denture retention was not as much of a research topic. Thus, total dentition retention has a direct connection with the patient's requirements and satisfaction [16].

The aim of this presentation was to point out another possibility in the prosthetic care of in opic patients, in conditions where there are no necessary possibilities for making satisfying classic total dentures.

\section{Patient View}

A patient at the age of 65 had a private health facility

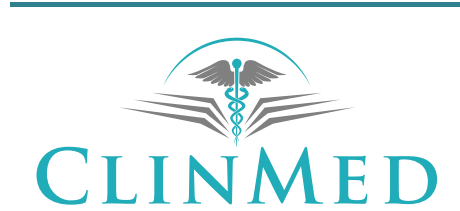

INTERNATIONAL LIBRARY
Citation: Tomić S (2019) Treatment of Edentulousness by Combined Implantation and Reduced Dentures: A Case Report. Int J Oral Dent Health 5:089. doi.org/10.23937/2469-5734/1510089 Accepted: May 25, 2019: Published: May 27, 2019

Copyright: @ 2019 Tomić $S$. This is an open-access article distributed under the terms of the Creative Commons Attribution License, which permits unrestricted use, distribution, and reproduction in any medium, provided the original author and source are credited. 
with a total dentures she was wearing for several years and she was not satisfied; due to the pronounced resorption of the alveolar ridge, the prostheses were completely unstable and dysfunctional in speech and mastication. The patient was a good general health condition, which she confirmed with her signature in a medical record, and denied any illness. After a clinical examination and analysis of $\mathrm{X}$-rays, the patients presented possible prosthetic solutions with all their advantages and disadvantages. Regardless of the proposed augmentation and the time needed for the jaws to be ready for the optimal number of implants, the patient nevertheless decided, in agreement with us, to make a compromise solution-the installation of a small number of implants

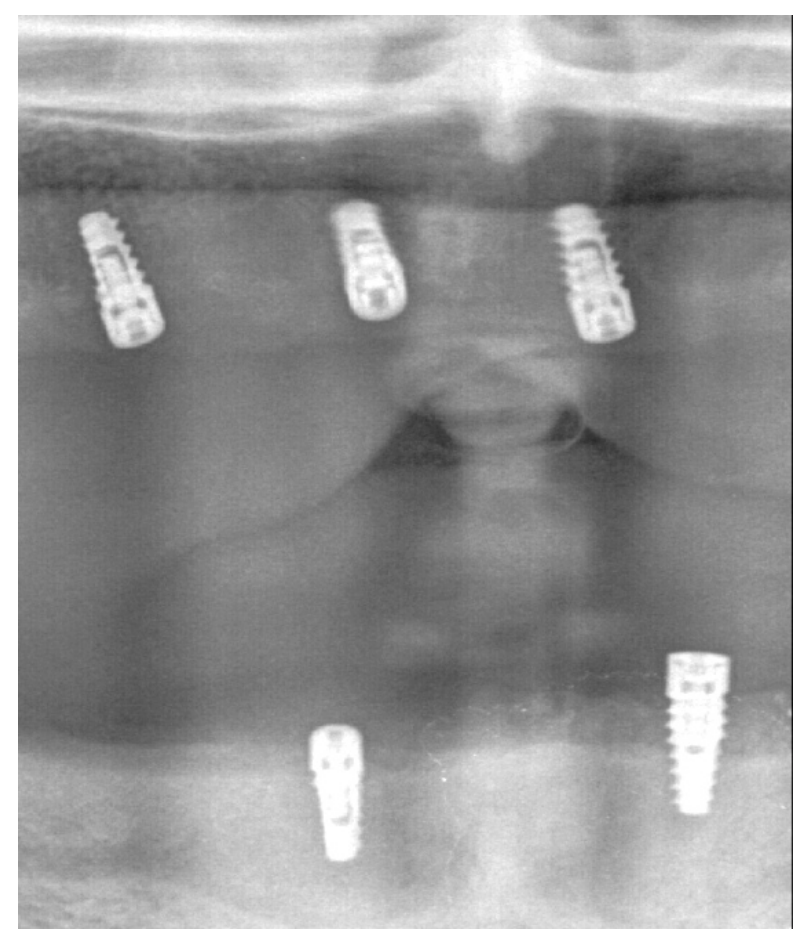

Figure 1: Three implants were inserted in the upper jaw, and two implants in the lower jaw. that, thanks to the built-in bar connecting their suprastructures, could Successfully carry new total dentures.

Three implants were inserted in the upper jaw, and two implants in the lower jaw. Two implants of dimensions $(3.8 \times 9 \mathrm{~mm})$ were embedded in the lateral upper incisor and second premolar position on the right, as well as in the position of the central incisor from the left side. In the lower jaw, for the same reasons (pronounced atrophy of the residual alveolar ridge) implants $(3.8 \times 9 \mathrm{~mm})$ were implanted in the lateral incisor region on the right and the implant size $(3.8 \times 10 \mathrm{~mm})$ in the left side of the eyelid region (Figure 1 ).

After the completion of the period of osseointegration, about three months later, the patient appeared and on the implants the gingiva-formers were worn for four weeks. After a complete successful surgical preparation, a prosthetic part followed, where in the technique Dolder's cross was made, intended for both jaws (Figure 2).

After the trial was satisfactory, the definitive dentures were made and the Dolder's bar inserted onto the implants and their screws (Figure 3). In the last visit to the patient, a definitive work was completed, which was fulfilled by our patient, and, most importantly, her expectations (Figure 4).

\section{Discussion}

Plate total prostheses, many authors agree, should be light, comfortable, to provide perception of taste and food temperature, as well as to improve phonation, chewing and swallowing [17-22]. Reduction of the prosthesis causes a reduction in its retention [1,8,23,24]. In order to reduce the denture plate, and not to reduce the desirable characteristics of total protease, it is preferable to install at least four implants in each jaw [4$8,23]$.

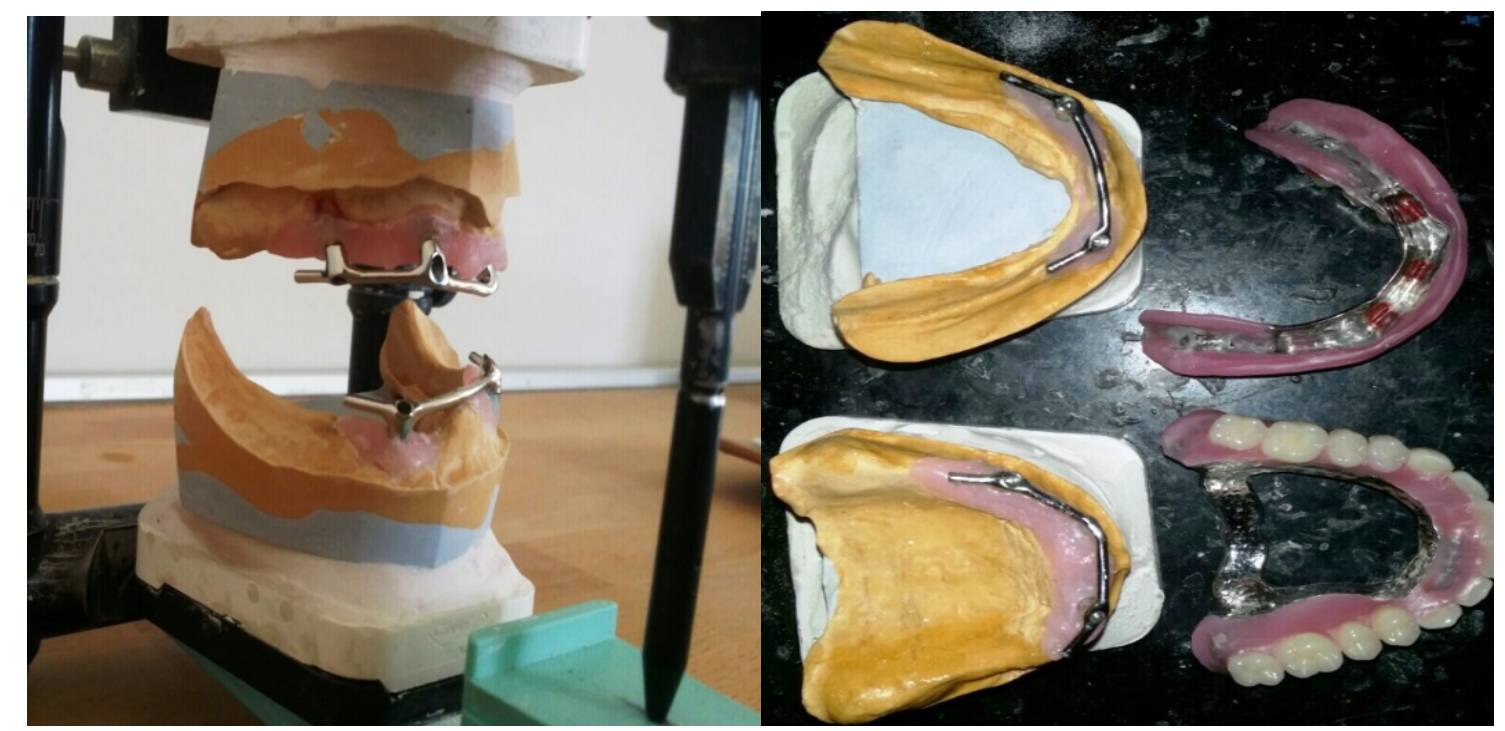

Figure 2: Dolder's cross was made after the period of osseointegration, intended for both jaws. 


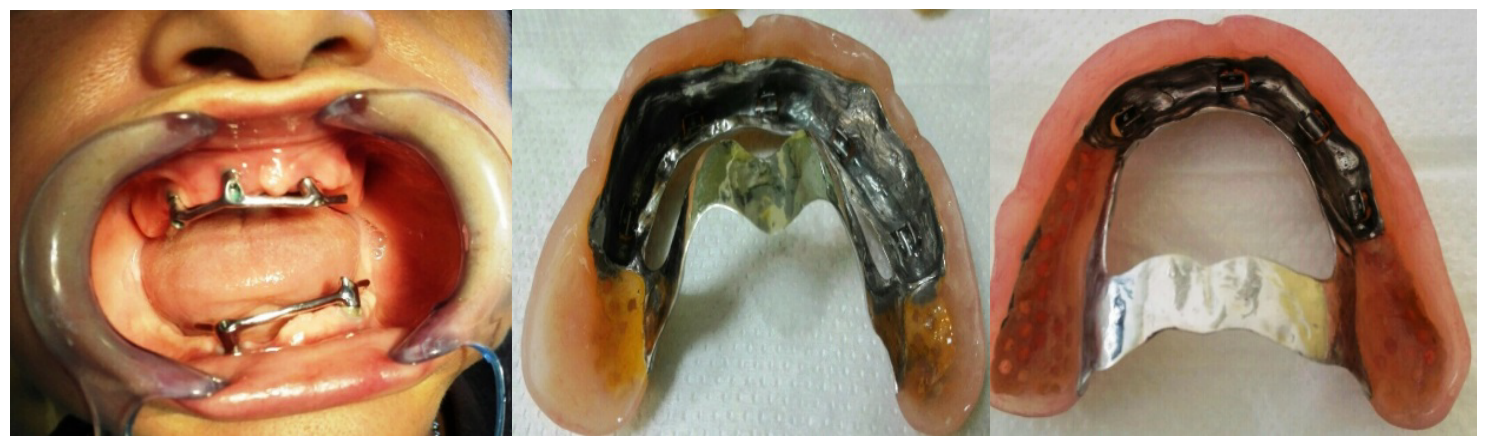

Figure 3: Dolder's bar inserted onto the implants and their screws, after the trial was satisfactory.

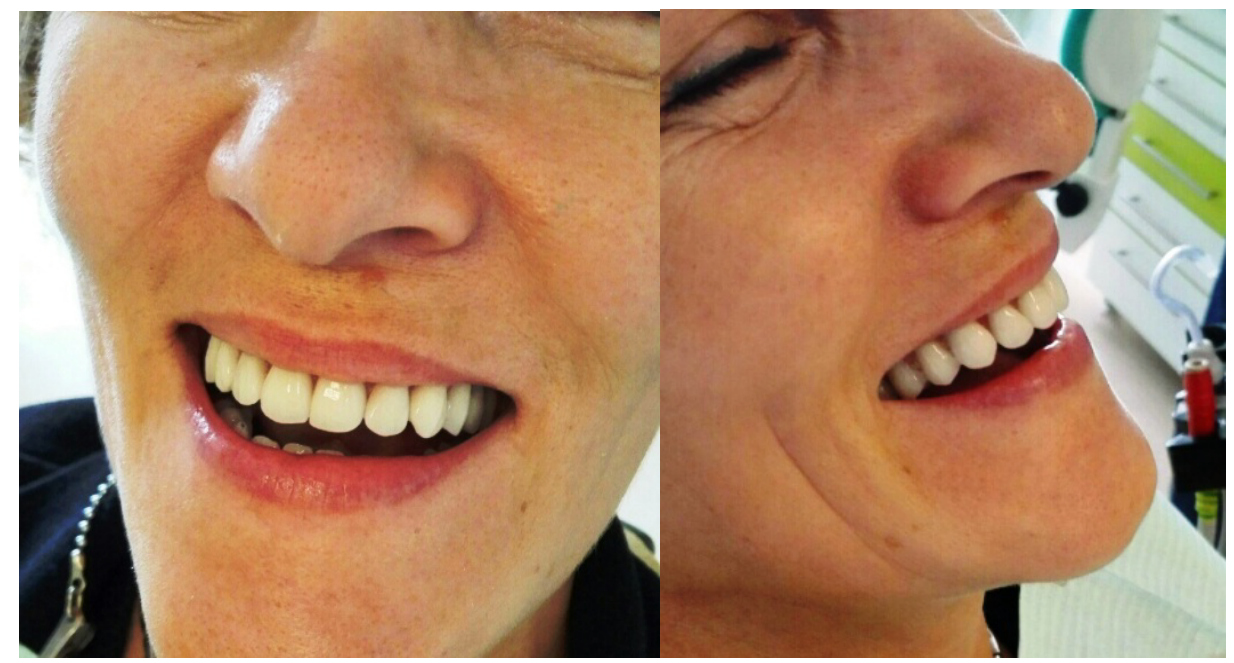

Figure 4: Last visit of patient to the hospital.

With the patient shown, in agreement with the prosthetist and prosthetics technician, respecting static principles, we made a compromise, while preserving the stability of the stroke, where the patient could normally chew and speak, without fear that the prosthesis would fall out. We are also pleased with the exceptional aesthetic achievement, because the dental liners in both jaws compensated the spongy ridge in the horizontal projection, and, on the patient's satisfaction, we managed to roughly achieve the physiognomy that it had before the loss of the teeth.

The rate of success of this form of therapy depends on the correct choice of the patient, the sufficient number of implants, their satisfying diameter and length, and the favorable distribution of occlusal load [8]. All patients want reduced palate coverage due to the mentioned advantages in phonation, chewing and swallowing, with which other authors agree $[8,25]$. In addition, the implant site localization plays an important role in the retention and stabilization of the prosthesis $[12,26,27]$. Retinal implant prostheses represent treatment choices for people who do not have anatomical conditions for retention and stability of classic total prostheses, but also for those who have the profession and the quality of daily life on the list of priorities.

\section{References}

1. Misch CE (2005) Partial and complete edentulous maxilla implant treatment plans: Fixed and overdenture prostheses. In: Dental implant prosthetics. St. Louis: Mosby, 281-294.

2. Närhi TO, Hevinga M, Voorsmit RA, Kalk W (2001) Maxillary overdentures retained by splinted and unsplinted implants: A retrospective study. Int $\mathrm{J}$ Oral Maxillofac Implants 16: 259-266.

3. Ochiai KT, Williams BH, Hojo $S$, Nishimura R, Caputo AA (2004) Photoelastic analysis of the effect of palatal support on various implant-supported overdenture designs. J Prosthet Dent 91: 421-427.

4. Lewis S, Sharma A, Nishimura R (1992) Treatment of edentulous maxillae with osseointegrated implants. J Prosthet Dent 68: 503-508.

5. Vogel RC (2008) Implant overdentures: A new standard of care for edentulous patients current concepts and techniques. Compend Contin Educ Dent 29: 270-276.

6. Mericske-Stern R (1998) Treatment outcomes with implantsupported overdentures: Clinical considerations. J Prosthet Dent 79: 66-73.

7. Kiener P, Oetterli M, Mericske E, Mericske-Stern R (2001) Effectiveness of maxillary overdentures supported by implants: Maintenance and prosthetic complications. Int J Prosthodont 14: 133-140.

8. Cavallaro JS Jr, Tarnow DP (2007) Unsplinted implants retaining maxillary overdentures with partial palatal coverage: Report of 5 consecutive cases. Int $\mathrm{J}$ Oral Maxillofac Implants 22: 808-814. 
9. Misch CE, Silc JT (2009) A key implant position for a fixed prosthesis: The first molar rule. Oral health.

10. Malo P, Nobre M (2008) The "All-on-4" implant concept for edentulous jaws. Implant Trib 3: 6-11.

11. Widbom C, Söderfeldt B, Kronström M (2005) A retrospective evaluation of treatments with implant-supported maxillary overdentures. Clin Implant Dent Relat Res 7: 166-172.

12. Michelinakis G, Barclay CW, Smith PW (2006) The influence of interimplant distance and attachment type on the retention characteristics of mandibular overdentures on 2 implants: Initial retention values. Int J Prosthodont 19: 507-512.

13. Cohen BI, Pagnillo M, Condos S, Deutsch AS (1996) Comparative study of two precision overdenture attachment designs. J Prosthet Dent 76: 145-152.

14. Williams BH, Ochiai KT, Hojo $S$, Nishimura R, Caputo AA (2001) Retention of maxillary implant overdenture bars of different designs. J Prosthet Dent 86: 603-607.

15. Chung KH, Chung CY, Cagna DR, Cronin RJ Jr (2004) Retention characteristics of attachment systems for implant overdentures. J Prosthodont 13: 221-226.

16. Naert I, Quirynen M, Theuniers G, van Steenberghe D (1991) Prosthetic aspects of osseointegrated fixtures supporting overdentures. A 4-year report. J Prosthet Dent 65: 671-680.

17. Furuya-Yoshinaka $M$, Yoshinaka $M$, Isogai $F$, Maeda $Y$ (2009) Influence of an experimental palatal plate on thermal perception. J Prosthodont Res 53: 193-196.

18. Engelen L, Prinz JF, Bosman F (2002) The influence of density and material on oral perception of ball size with and without palatal coverage. Arch Oral Biol 47: 197-201.
19. Kumamoto Y, Kaiba Y, Imamura S, Minakuchi S (2010) Influence of palatal coverage on oral function - Oral stereognostic ability and masticatory efficiency. $J$ Prosthodont Res 54: 92-96.

20. Kaiba Y, Hirano S, Hayakawa I (2006) Palatal coverage disturbance in masticatory function. J Med Dent Sci 53: 1-6.

21. Zhang $H$, Sone $M$, Yamamoto $H$, Ohmori $K$, Yaka $T$, et al. (2009) Influence of experimental palatal plate on mandibular position during continuous phonation of [n]. J Prosthodont Res 53: 38-40.

22. Kodaira Y, Ishizaki K, Sakurai K (2006) Effect of palate covering on bolus-propulsion time and its contributory factors. J Oral Rehabil 33: 8-16.

23. Engelman $M$ (1996) Clinical decision making and treatment planning in osseointegration. Quintes-sence Publishing. Chicago, 187-192.

24. Winter R (2009) Upgradeable dentistry, part 2. Dent Today 28: 97-98, 100.

25. de Albuquerque Júnior RF, Lund JP, Tang L, Larivée J, de Grandmont $P$, et al. (2000) Within-subject comparison of maxillary long-bar implant-retained prostheses with and without palatal coverage: Patient-based outcomes. Clin Oral Implants Res 11: 555-565.

26. Doukas D, Michelinakis G, Smith PW, Barclay CW (2008) The influence of interimplant distance and attachment type on the retention characteristics of mandibular overdentures on 2 implants: 6-month fatigue retention values. Int $\mathrm{J}$ Prosthodont 21: 152-154.

27. Tabatabaian F, Sabouri A, Sobhani Z (2012) Effect of interimplant distance on retention and stability of overdenture. Rotterdam, Netherlands: Proceedings of the 36th Annual Conference of the European Prosthodontic Association. 